University of Rhode Island

DigitalCommons@URI

Open Access Dissertations

1974

\title{
Symptom and Dynamic Hierarchies in the Systematic Desensitization of Test Anxiety: An Incentive Approach
}

William A. Hancur

University of Rhode Island

Follow this and additional works at: https://digitalcommons.uri.edu/oa_diss

\section{Recommended Citation}

Hancur, William A., "Symptom and Dynamic Hierarchies in the Systematic Desensitization of Test Anxiety: An Incentive Approach" (1974). Open Access Dissertations. Paper 972.

https://digitalcommons.uri.edu/oa_diss/972

This Dissertation is brought to you for free and open access by DigitalCommons@URI. It has been accepted for inclusion in Open Access Dissertations by an authorized administrator of DigitalCommons@URI. For more information, please contact digitalcommons-group@uri.edu. 


\author{
SYMPTOM AND DYNAMIC \\ HIERARCHIES IN THE SYSTEMATIC \\ DESENSITIZATION OF TEST ANXIETY: \\ AN INTEGRATIVE APPROACH
}

BY

WILLIAM A. HANCUR

A DISSERTATION SUBMITTED IN FARTIAL FULFILLNENT OF THE REQUIREMENTS FOR THE DEGREE OF DOCTOR OF PHILOSOFHY

IN

PSYCHOLOGY

UNIVERSITY OF RHODE ISLAND 


\section{ABSTRACT}

This study proposed to determine the effectiveness of systematic desensitization with integrative, symptom and dynamic hierarchies. It was hypothesized that systematic desensitization with integrative hierarchies would be more effective in reducing disruptive test anxiety than systematic desensitization with either symptom or dynamic hierarchies alone. It was further hypothesized that systematic desensitization with both integrative and dynamic hierarchies would be superior to systematic desensitization with symptom hierarchies in generalization to anxieties associated with test anxiety.

Forty-four test anxious college males were randomiy assigned to one of four treatment groups: 1) a symptom group treated with systematic desensitization based on cues related symptomatically to test anxiety; 2) a dynamic group desensitized with hierarchies based on the underlying dynamics of test anxiety; 3) an integrative group treated with systematic desensitization based on cues related both symptomatica11y and dynamical1y to test anxiety; and, 4) a no-treatment control group. Following four sessions of group desensitization, the symptom, dynamic and integrative groups all reported significant reductions on the ApertHaber Test Anxiety Scale, the Wonderlic Personnel Test and the Wolpe Fear Thermometer. The dynamic group yjelded a 
significantly greater reduction in self-reported anxiety on the Wolpe Fear Thermometer than did the symptom group. The integrative group also reported a significant reduction on the evaluative factor of the Wolpe Fear Inventory. These results indicate that systematic desensitization with symptom, dynamic or integrative hierarchies are each effective treatments of disruptive test anxiety. They also suggest that systematic desensitization with integrative hierarchies is effective in reducing general evaluative anxiety associated with the target symptom and may be a superior treatment overal1. This study therefore supports an integrative theory (Stampfl and Levis, 1.967 ; Prochaska, 1971; Hancur and Prochaska, 1973) which conceives of test anxiety as a combination of anxiety attached to both symptom and dynamic cues. 


\section{ACKNOWLEDGENENTS}

I would like to express my sincere appreciation to my Dissertation Committee: Dr. James Prochaska, Chairman, Dr. Alan Willoughby and Dr. Richard Travisano for their assistance in the development and preparation of this dissertation. Their criticism, support and encouragement were tremendously helpful at every phase of the dissertation process.

I would especially like to thank Drs. Willoughby and Prochaska who have each been instructor, colleague and friend to me throughout my training.

I wish, too, to thank Mr. Norman DuPont who served as co-experimenter.

Finally, to my wife, Mary, and daughter, Sarah, who each day give my 1 ife added meaning. 


\section{TABLE OI CONTENTS}

LIST OF TABLES

INTRODUCTION
Subjects
Dependent Measures
Treatment Conditions
Procedure

RESULTS

17

DISCUSSION

25

REFEREN CES

30

APPENDIX A

APPENDIX B 
Table

Page

1. Means and standard deviations for changes in scores from pretesting to posttesting on the Wonderlic Personnel Test and Wolpe Fear Thermometer.

2. Duncan Multiple Range matrix for differences among change score totals on the Wonderlic Personnel Test.

3. Duncan Multiple Range matrix for differences among change score totals on the Wolpe Fear Thermometer.

4. Means and standard deviations for changes in scores from pretesting to posttesting on the Alpert-Haber Test Anxiety Scale.

5. Duncan Multiple Range matrix for differences among change score totals on the Alpert-Haber Test Anxiety scale.

6. Means and standard deviations for changes in scores from pretesting to posttesting on the Wolpe Fear Inventory.

7. Duncan Multiple Range matrix for differences among change score totals on the wolpe Fear Inventory.

8. Duncan Multiple Range matrix for differences among change score totals on the evaluation factor of the Wolpe Fear Inventory. 


\section{INTRODUCTION}

With the advent of Wolpe's (1958) behavior therapy, a destructive split began to grow in cilinical practice between those therapists who dealt primarily with target symptoms, that is, anxiety. attached to environmental stimuli in the present, and those who concentrated on dynamic forces assumed to underlie target symptoms, for example, repressed thoughts and impulses which grow out of past experiences and relationships.

Recent $1 y$, several attempts have been made to repair this rift. Stampfl and Levis (1967) produced an integrative therapy with their implosive technique which depends on both symptom and dynamic material in the construction of impiosive scenes. In an empirical study utilizing implosive therapy, Prochaska (1971) was able to demonstrate that both symptom and dynamic scenes were effective in relieving a target symptom. Similarly, Hancur and Prochaska (1973) studied the effectiveness of dynamic and symptom cues in systematic desensitization and found them both to be effective in reducing test anxiety. Feather and Rhoads (1972) report case studies of some obsessivecompulsive disorders in which they considered dynamic forces in modifying their beinavioral technique but they did no systematic empirical work in evaluating the contribution of these modifications to the overall effectiveness 
of the treatment.

Since both symptom and dynamic cues have been shown to be effective in reducing target symptoms with implosive therapy and systematic desensitization, it is important to begin to evaluate a three-factor approach in which a given target symptom, for example test anxiety, is construed as having anxiety deriving from three sources. One source is the environmental situation itself (fear of failing a test); a second source is the underlying psychodynamics of the symptom (fear of criticism and retaliation by parents); and the third source, an interaction of the two (fear of failure on a test generating criticism and retaliation by parents). From this viewpoint, a treatment which deals with both symptom anxiety and dynamic anxiety in an interactional manner is expected to yie $1 \mathrm{~d}$ a greater reduction in anxiety than either a symptom or dynamic approach alone.

In reviewing the behavior modification literature utilizing these factors, one finds substantial work dealing with environmental, or target, symptoms exclusively (Emery, 1967; Kondas, 1967 ; Emery and Krumboltz, 1967; Suinn, 1968; Donner and Guerney, 1969 ; and Freeling and Shemberg, 1970). These studies repeatedly report significant reductions in target symptoms.

A revies of the behavior modification research irvolving the dynamic factor reveals four relevant studies. 
Kamil (1970), in an effort to reduce castration anxiety, desensitizt:d Ss to snake phobias. His results indicated that removal of a target symptom produces some reduction in underlying dynamic anxiety. Elenewski (1971) imploded Ss with dynamic cues of death anxiety and found significant reductions in the target symptom of insomia, thereby supporting the assumption of dynamic causation. Prochaska (1971) studied the effectiveness of symptom and dynamic cues in the implosive treatment of test anxiety and found them both to be effective, but neither superior, in anxiety reduction. Similarly, Hancur and Prochaska (1973) utilized symptom and dynamic cues in the systematic desensitization of test anxiety. Their results indicated that both symptom and dynamic cues are effective in reducing test anxiety but that no differential effectiveness could be demonstrated. Elenewski (1971), Prochaska (1971) and Hancur and Prochaska (1973), all lend support to the position that reduction in dynamic anxiety leads to significant reduction in target symptoms.

The scarcity of behavior modification research with dynamic stimuli is probably due to the fact that strict behaviorists, who regard dynamic forces as irrelevant, are doing most of the research with behavior therapy techniques.

A third approach has been implemented by implosive therapists who combine symptom and dynamic cues in the construction of implosive scenes. Several studies (Stampfl 
and Levis, 1967; Levis, 1967; and Hogan, 1966) report high degrees of success over a wide: range of psychopathology with implosive therapy. Although this integrative approach has been effective in reducing target symptoms, no empirical investigation has evaluated the relative contribution of each factor.

The present study extends the work of Prochaska (1971) and Hancur and Prochaska (1973) with test anxiety by developing an integrative systematic desensitization which uses symptom and dynamic cues in the construction of its hierarchies. Both studies indicated that symptom and dynaic hierarchies wére effective in reducing test anxiety but that neither was superior in anxiety reduction. Although the precise nature of the relationship between symptom and dynamic cues could not be determined from these studies, the results do indicate that the effects of symptom and dynamic cues are to some extent independent and therefore account for different parts of the total variance. This suggested that an integrative approach, utilizing both sets of cues, would result in a greater reduction in test anxiety than either a symptom or dynamic approach alone.

It was therefore hypothesized that systematic desensitization with integrative or combined hierarchies would result in sjgnificantly greater reductions in test anxiety than with either a symptom or dynamic hierarciy 
alone. Such a finding would lend support to a threefactor theory of symptom production and also provide the clinician with an effective therapeutic tool.

As a replication of Hancur and Prochaska (1973), it was also expected that systematic desensitization with either symptom or dynamic cues alone would result in a significant reduction in test anxiety as compared to notreatment.

Dynamic theories, as opposed to symptom-specific theories, predict generalization from one target symptom to another if underlying dynamic conflicts have beer reduced. From tis viewpoint, it was therefore hypothesized that effective treatment of test anxiety with dynamic and integrative systematic desensitization would result in greater generalization of anxiety reduction as compared to either symptom desensitization or no-treatment.

Test anxiety is appropriate for study since a well articulated dynamic base has been hypothesized by Sarason et. a1. (1960) for this symptom. In their formulation, test anxiety is regarded as resulting from the student's transference of certain conflicts with his parents inco his relationship with his teachers. They hypothesize that prior to school the high test anxious child has been negatively evaluated by his parents. The child is frustrated and angered by this evaluation but he is afraid to express this anger out of fear-- far of 
retaliation by his father and fear of losing the love and affection of his parents. Sarason et. al. (1960) further state that, in test situations, the student reacts to his teacher as if he were his parent and to the test situation as if it were his parents' means of evaluating him. His anger over such evaluation is aroused but so is his fear of retaliation and loss of affection. It is this fear that the student experiences as test anxiety. 


\section{METHODOLOGY AND PROCEDURE}

Subjects

E announced in large lecture classes that he was conducting a study with a new therapy that was intended to reduce disruptive test anyiety. The study was described as presently being limited to men who met the following criteria: a) zeport high levels of anxiety on tests; b) believe that this anxiety interferes with test performance; and c) are willing to volunteer six hours of their time during the remainder of the semester in an attempt to reduce this disruptive anxiety.

of those students who met these preselection criteria, this study included only those who scored at least one standard deviation higher on the Alpert-Haber Test Anxiety Scale than the average for the total sample in the original Alpert and Haber (1961) study. The average score for all Ss was 67.04. This compares to a mean of 44.05 in the Alpert and Haber (1961) study, thereby indicating that the $\underline{S}$ in this study were highly test all xious.

Sixty-four test anxious males were pretested and then randomly assigned to either a symptom desensitization $(n=13)$, dynamic desensitization $(n=13)$, integrative desensitization $(n=13)$ or no-treatment group $(n=25)$. Two Ss were lost fion each group leaving a total sample of 
fifty-six; one $\underline{S}$ from each of the treatment groups left during the treatment itself. Two of these were due to illness and the third left for no stated reason. of the remaining five $\underline{S}$, three never began treatment and two, who had been assigned to the no-treatment group, did not return for posttesting. There was no evidence of any systematic bias in the 1 oss of subjects. Eleven $\underline{\text { Ss }}$ were chosen randomly from the no-treatment group in order to achieve equal n's for statistical analysis.

Dependent Measures

Alpert-Haber Test Anxiety Scale. The same fort of this test was administered twice and all nineteen items in this scale were scored for debilitating test anxiety. Higher scores on this scale indicate higher levels of disruptive test anxiety. This scale was chosen because of its ability to differentiate test anxiety that leads to better performance from test anxiety that leads to poorer performance (Alpert and Haber, 1961). Effective treatment of test anxiety was expected to result in significantly lower scores.

Wonderlic Personne1 Test. The same form (A) of this test was given twice. No significant practice effect was anticipated since the test-retest interval was approximately six weeks. The test was introduced as an intelligence scale that nas designed to test the $\underline{S}^{\prime}$ s intellectual 
ability. The standard twalve minute time limit was used. This test was assumed in this study to be a paradigm of testing situations in which the disruptive effects of test anxiety should result in lowered performance due to the somewhat threatening nature of the evaluation, that is intelligence and the pressure of a time limit; this test was used successfully by Prochaska (1971) and Hancur and Prochaska (1973) as a measure of reduction in disruptive test anxiety. Effective treatment of test anxiety was expected to result in higher scores.

Wolpe Fear Thermometer. This is a 100 point scale with zero representing the most relaxed a person has ever felt and 100 representing the most anxious. This scale was used as a self-report anxiety measure after administration of the Wonderlic Personnel Test with Ss being asked to rate how anxious or relaxed they felt while taking the test; this scale has been used successfully by Prochaska (1971) and by Hancur and Prochaska (1973) with test anxiety and by Wolpe (1958) with a variety of fear situations. Effective treatment of test anxiety was expected to result in lowered scores.

Wolpe Fear Inventory. The same form of this test was given twice. Ss were instrucced to rate how anxious they felt in the presence of situations or objects which, 
for the purpose of this study, are assumed to be associated with test anxiety from a dynamic viewpoint (Sarason et. al. 1960). The rating was made on a five point scale ranging from Not At A11 to Very Much. Although the entire seventy-nine item fear inventory was presented, only the forty-four items loading on three relevant factors (eva1uation, separation and physical damage) and accounting for $45.3 \%$ of the total variance, were scored and used as a measure of generalization of anxiety reduction. The statistical basis for this. forty-four item scoring is provided by Bates (1971). Items by factors can be found in Appendix A. Effective dynamic treatment of test anxiety was expected to result in greater generalization and therefore lower scores.

\section{Treatment Conditions}

\section{Symptom Desensitization. The following sixteen}

item hierarchy is identical to that developed by Emery and Krumboltz (1967) and used successfully by Hancur and Prochaska (1973). The order of presentation was standardized as follows:

1. The teacher announces and discusses a course examination (to be held in three weeks) with the class.

2. Studying for an important examination that is two weeks away. 
3. Studying for an important examination that is one week away.

4. Studying for an important examination that is two days away.

5. Studying for an important examination that is the next day.

6. Discussing an important examination with friends the night before the exam.

7. Going to sleep the night before the important examination.

8. It is the day of the examination-- one hour left until exam time.

9. Laaving your room at your living quarters to go to the important examination.

10. Entering the room where the examination is being given and sitting down.

11. The examination is being handed out-- you receive a copy.

12. Reading over the instructions to the important examination and surveying the test.

13. Taking the important examination and working on a question to which you know the answer.

14. Taking the important examination and working on a question to which you do not know the answer.

15. While trying to think of an answer to an examination question, you notice everyone around you writing very rapidly.

16. Having thirty minutes left to complete the examination and an hour's worth of work to do.

Dynamic Desensitization. The following sixteen

item hierarchy is based theoretically on Sarason's (1960)

dynamic hypothesis of test anxiety and is identical to 
that used by Hancur and Prochaska (1973) who found it to be effective in reducing disruptive test anxiety. These items are ordered according to their assumed ability to elicit anxiety - from criticism through physical abuse to loss of affection. The rationale for this order is provided by Sarason's (1960) dynamic theory of test anxiety. The order of presentation was standardized as follows:

1. You have to paint the living room of your home.

2. While painting, you spill a little paint on the rug.

3. Your parents are criticizing you for the paint on the rug.

4. Your parents are harping about how stupid you are.

5. You are feeling angry at your parents over their criticizing you.

6. You are cussing your parents out over their getting on your back.

7. You are telling your parents to get off your back.

8. Your father is telling you to shut your mouth and to mind your manners.

9. Your father is slapping your face because you cussed him out.

10. Your father knocks you down to the ground.

11. Your father stomps on your middle finger.

12. Your father kicks you in the groin.

13. Your father pulis your pants down and. stomps on your peais. 
14. Your father is cutting your penis off with a knife.

15. Your parents are telling you to pack your bags.

16. Your parents are telling you to get out of the house and to stay out.

Integrative Desensitizaticn. The following

sixteen item hierarchy was developed in order to test the hypotheses of this study and is derived from the preceding symptom and dynamic hierarchies used by Hancur and Prochaska (1973). The order of presentation was standardized as follows:

1. Studying for an important examination that is one week away.

2. Your parents call the night before the exam to tell you to do well.

3. Going to sleep the night before the important examination.

4. Entering the room where the examination is being given and sitting down.

5. The examination is being handed out-you receive a copy.

6. While trying to think of an answer to an examination question, you notice everyone around you writing very rapidly.

7. Having thirty minutes left to complete the examination and an hour's worth of work to do.

8. You think you have done very poorly on the important examination.

9. You get the examination back and your grade is F. 
10. You go home ard tell your parents that you flunked tire important $\in$ xam.

11. Your parents are harping about how stupid you are for flunking the exam.

12. You are feeling angry at your parents over their criticjzing you and tell them to shut-up.

13. Your father is slapping your face because you told him to shut-up.

14. Your father kicks you in the groin.

15. Your father pulls your pants down and cuts your penis off with a knife.

16. Your parents are telling you to pack your bags and to get out.

No-Treatment. This was a no-contact control group.

Control of other relevant variables. Based on the conclusions of many studies on systematic desensitization (Wilkins, 1971; Wolpe, 1973), this study assumes that systematic desensitization is an effective treatment of anxiety and further, that it is more effective than placebo treatments. This study does not ignore so-called "placebo" effects, such as expectation of result, but rather agrees with Wilkins' (1971) conclusions that expectation of result is one of the six factors necessary for effective systematic desensitization. Five of these six factors will be controlled by holding them constant across treatment groups, with the sixth, namely content of hierarchy, being experimentally raripulated. 
Procedure

All Ss were pretested in ore session with the tests being presented in the following order: Wonderlic Personnel Test (Form A), Wolpe Fear Thermometer, AlpertHaber Test Anxiety Scale and Wolpe Fear Inventory. Prior to the first therapy session, Ss meeting pre-selection criteria were randomly assigned to either a symptom desensitization, dynamic desensitization, integrative desensitization or no-treatment group. Ss assigned to treatment groups were informed of their appointment times. The no-treatment group was told that the facilities were full at the present time and that they would be contacted when there was room available for treatment. (Treatment was, in fact, offered to this group after posttesting was completed.) Two therapists, both advanced clinical graduate students trained in systematic desensitization, conducted the treatment. The procedure utilized by both therapists was standardized by following the basic guidelines for effective group desensitization described by Lazarus (1961). The author had two sections in each treatment group (total $\mathrm{n}=17$ ), while the other therapist had one section in each group (total $n=16$ ). Section size ranged from a minimum of two to a maximum of six.

The study was conducted in two phases spanning four months with one therapist having three treatment groups in each phase while the other had three treatment groups 
in only the second phase. Group desensitization with standardized hierarchies was used in accordance with the methods employed successfully by Lazarus (1961) and endorsed by Wolpe (1973). 포 were taught deep muscle relaxation in the first hourly session, followed by three hourly sessions of desensitization. Besides using group desensitization and standardized hierarchies, the therapy followed Wolpe's $(1958 ; 1973)$ original procedure including instructing $\underline{S}$ s to practice relaxation between treatment sessions. The treatment proceeded until all items in the hierarchy had been presented.

The pace of preseritation was monitored within sessions in order to control for amount of time actually spent in desensitization. All Ss were exposed to approximately two and one-half hours of desensitization over four sessions. Upon completion of treatment, a 11 remaining Ss and the no-treatment controls were again tested with the Wonderlic Personnel Test (Form A), followed by the Wolpe Fear Thermometer, Alpert-Haber Test Anxiety Scale and Wolpe Fear Inventory. These were given in the same order as in pretesting. The entire procedure from preto posttesting took six weeks with a three week interval between pretesting and the first treatment session. 


\section{RESULTS}

One-way analysis of variance was used to test differences among group means. Because most of the individual comparisons were based on predictions, the more liberal Duncan-Multiple Range procedure was used. Because this is a two-tailed procedure, the .10 1evel was accepted where the direction of the difference was predicted.

\section{Wonderlic Personnel Test (WP)}

One of the principal means of testing the effectiveness of any psychotherapy is to measure changes in performance following treatment. If test anxiety were reduced, it was expected that performance on an inte11igence test, namely the Wonderlic Personnel Iest, would increase. Table 1 shows the average charges in scores on the Wonderlic Pesonnel Test from pretesting to posttesting for the symptom desensitization (SD), dynamic desensitization (DD), integrative desensitization (ID) and no-treatment (NT) groups. Positive scores represent improved performance. 


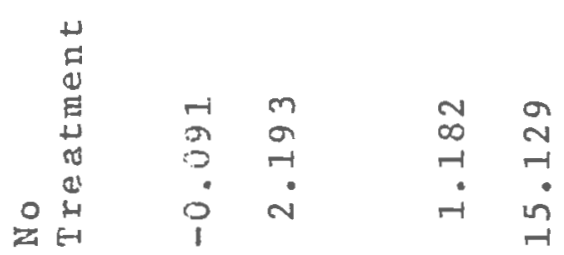
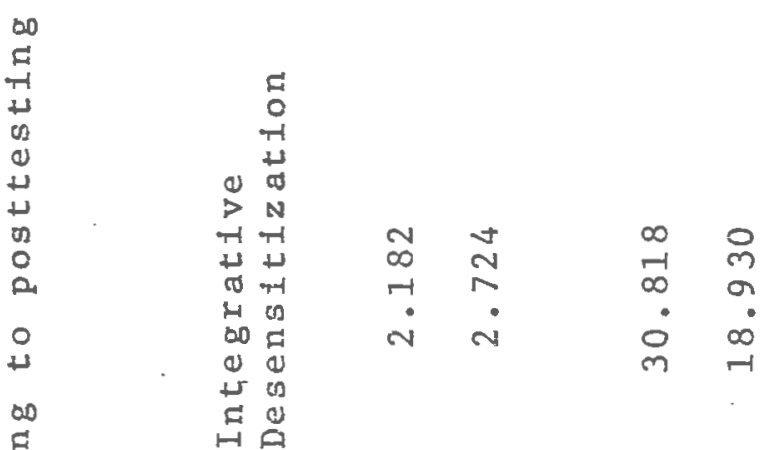

म

H

os

I)

4

क. :

\& 1

00

+ 를

4

\& 4

(1)

.

어

o 4

넌

व

가 5

(1)

क D

范

당

-

$\circ$

'十

os 0

든

다 त

$+0$

$\sigma E$

$\rightarrow$

(1) थ

a

a

s

का 0

क्ष

का 임

$\nabla \stackrel{5}{0}$

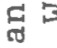

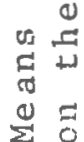

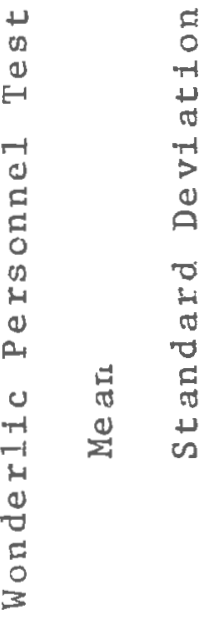

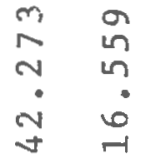

$\begin{array}{ll}N & \infty \\ N & 0 \\ \sim & m\end{array}$

s os

久ิ

$0+$

$\rightarrow$ en

E

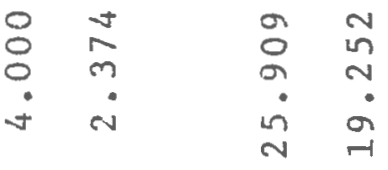

莫市

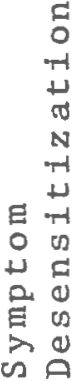

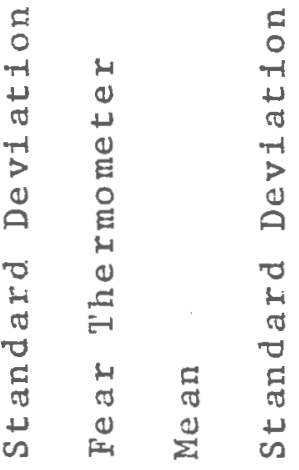

$\stackrel{0}{0}$ 
One-way analysis of varjance among groups in

Table 1 was significant beyond the .025 level with an $\underline{F}=4.250$. Raw data and source table for this analysis can be found in Appendix B.

Individual comparisons among the experimental

groups were made by means of the Duncan Muliple Range procedure. As predicted, there was a significant increase in change score cotals for the symptom, dynamic and integrative groups as compared to no-treatment. There was no significant difference in change score totals among the symptom, dynamic or integrative desensitization groups. Table 2 shows the matrix for differences among totals for Duncan Multiple Range analysis of changes in Wonderlic Personnel Test scores.

Table 2

Duncan Multiple Range matrix for differences among change score totals on the Wonderlic Personnel Test.
N T
I D
DD
SD

NT

25 *

$31 * *$

$45 * *$

I D

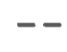

6

20

DD

14

SD

$$
\begin{array}{r}
* \mathrm{P}<.10 \\
* * \mathrm{P}<.05 \\
* * * \mathrm{P}<.01
\end{array}
$$


Wolpe Fear Thermometer (WT)

Table 1 presents the changes in self-reported anxiety from pretesting to posttesting for al1 groups while taking the Wonderlic Personnel Test. Positive scores represent reductions in self-reported anxiety. One-way analysis of variance among groups in Table 1 was significant beyond the .001 level. with an $\underline{F}=9.737$. Raw data and source table for this analysis can be found in Appendix B.

Individual comparisons among the groups yielded significant differences in totals for the three treatment groups as compared to the no-treatment group and for the dynamic group as compared to the symptom group.

Table 3 shows the matrix for differences among totals for Duncan Multiple Range analysis of changes in Wolpe Fear Thermometer scores.

Table 3

Duncan Multiple Range matrix for differences among change score totals on the Wolpe Fear Thermometer.

N T

N T

S D

I D

DD
$S D$

$272 \div$

$-$

54

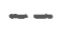

D D

$452 * x$

$180 *$

1.26

* $\mathrm{P}<.10$

$*$ * P $<.01$ 


\section{Alpert-Haber Test Anxiety Scale (A-H)}

Table 4 shows the average changes in scores from pretesting to posttesting for all groups on the AlpertHaber Test Anxiety Scale. Positive scores represent reductions in disruptive test anxiety.

\section{Table 4}

Means and Standard Deviations for changes in scores from pretesting to posttesting on the Alpert-Haber Test Anxiety Scale.

$\begin{array}{llll}\text { SD } & \text { DD } & \text { NT }\end{array}$

$\begin{array}{rrrrr}\text { Mean } & 3.000 & 4.454 & 5.909 & -3.000 \\ \text { S D } & 6.208 & 5.549 & 7.810 & 3.908\end{array}$

Analysis of variance among groups in Table 4 was significant beyond the .025 level with an $E=4.200$. Raw data and source table for this anaiysis can be found in Appendix B.

Individual comparisons among the groups yielded significant differences in change score totals for the symptom, dynamic and integrative desensitization groups as compared to the no-treatment group. No significant differences were found among the three treatment groups themselves. Table 5 presents the matrix for differences among totals for Duncan Multiple Range analysis of changes in Alpert-Haber Test Anxiety Scale scores. 
Table 5

Duncan Multiple Range matrix for differences among change score totals on the Alpert-Haber Test Anxiety Scale.

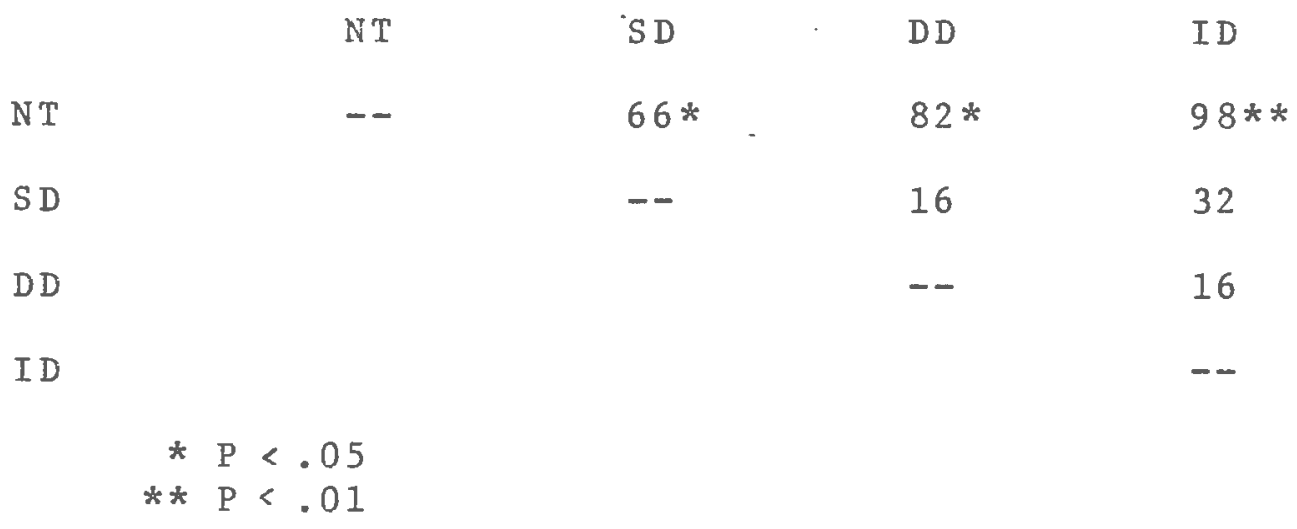

Wolpe Fear Inventory (WI).

As a measure of generalization from symptom anxiety to other anxiety situations, the Wolpe Fear Inventory was used.

Table 6 shows the average changes in scores from pretesting to posttesting for all groups on the Wolpe Fear Inventory. Positive scores represent reductions in anxiety on this inventory.

Table 6

Means and Standard Deviations for changes in scores from pretesting to posttesting on the Wolpe Fear Inventory.

S D

DD

I D

N T

Me an

4.273

3.727

13.818

$-0.636$

SD

13.403

9.564

21.438

10.928 
Analysis of variance among groups in Table 6 was significant at the .10 level with an $\underline{F}=2.194$. Raw data and source table for this analysis can be found in Appendix B. Individual comparisons among the groups yielded a significant difference in totals between the integrative desensitization group, and the no-treatment group. No significant differences in totals among the treatment groups were found. Table 7 shows the matrix for differences among totals for Duncan Multiple Range analysis of changes in Wolpe Fear Inventory scores.

\section{Table 7}

Duncan Multiple Range matrix for differences among change score totals on the Wolpe Fear Inventory.
N T
DD
S D
I D

N T

48

54

$159 *$

D D

$--$

6

SD

$--\quad 105$

I D

$$
\text { * } \mathrm{P}<.05
$$

While the differences between integrative systematic desensitization and both dynamic and symptom systematic desensitization were not significant at the .10 level, the levels of significance that were attained are worth noting. For integrative systematic desensitization versus dynamic systematic desensitization, a value of 2.514 was needed for significance at the .10 level. The value obtained was 2.466. 
Similarly, for integrative systematic desensitization versus symptom systematic desensitization, a value of 2.381 was needed for significance at the.10 level. The obtained value was 2.333 .

In order to better understand the obtained differences on the Wolpe Fear Inventory, the three individual factors comprising the inventory were analyzed. A significant difference was found between the integrative systematic desensitization group and the no-treatment group on the evaluative factor. No significant differences were found among the treatment groups on this factor. Table 8 shows the matrix for differences among totals for Duncan Multiple Range analysis of changes in scores on the evaluative factor of the Wolpe Fear Inventory.

\section{Table 8}

Duncan Multiple Range matrix for differences among change score totals on the evaluative factor of the wolpe Fear Inventory.

$$
\begin{array}{llll}
\text { NT } & \text { DD } & \text { SD } & \text { ID }
\end{array}
$$

N T

$\mathrm{DD}$

I D

$* \mathrm{P}<.05$

No other significant differences vere found among groups on efther the separation or physical damage factors. Raw data for these analyses can be found in Appendix B. 


\section{DISCUSSION}

This study proposed to determine the effectiveness of an integrative systematic desensitization of test anxiety. It was hypothesized that systematic desensitization with integrative hierarchies would be more effective in reducing disruptive test anxiety than systematic desensitization with either symptom or dynamic hierarchies alone. This hypothesis was not supported by the data.

The data do lend strong support to the overal1 effectiveness of systematic desensitization with integrative hierarchies in reducing disruptive test anxiety. On all three test anxiety measures, integrative systematic desensitization led to significant reductions. These findirgs were also made for systematic desensitization with either symptom or dynamic hierarchies. In fact, on only one measure was there a significant difference among the three treatment groups. That finding was made for self-reported anxiety while performing on an intelligence test and it indicates that systematic desensitization with dynamic hierarchies is superior to systematic desensitization with symptom hierarchies in reducing self-reported, state anxiety. These results are consistent with the findings of Prochaska (1971) and Hancur and Prochaska (1973) in that the target symptom of disruptive test arixiety was able to be reduced by both symptom and dynamic cues thereby supporting a combinarion theory of symptom production and removal 
(Stampfl and Levis, 1967).

A second hypothesis stated tiat systematic desensitization with both integrative and dynatic hierarchies would lead to greater generalization of anxiety reduction than would systematic desensitization with symptom hierarchies. The data here suggest that, compared to symptom systematic desensitization, integrative systematic desensitization led to significantiy greater generalization ( $P$ < 05). Specifically, the greater generalization produced by integrative systematic desensitization was from test anxiety to general evaluative anxiety.

While integrative systematic desensitization does not appear to be superior to symptom systematic desensitization in reducing a particular target symptom, namely test anxiety, it did, under the conditions of this study, produce significantly greater generalization to other evaluative anxiety situations. This greater generalization effect of integrative systematic desensitization may be due to the fact that the integrative hierarchy samples more stimulus situations than does the symptom hierarchy. The symptom hierarchy focuses on evaluative anxiety related only to tests and test situations. The integrative hierarchy on the other hand, focuses on evaluative anxiety related not only to tests but also to such situations as parental criticism. That the dynamic systematic desensitization did not result in significant reductions in evaluative anxiety is 
less easily explained. It inay be that in order to achieve generalization to the evaluative factor, it is insufficient to treat just the stimuli of parental criticism without also dealing with the interaction of academic and parental evaluation .

While it was expected from Sarason's (1960) work that the integrative systematic desensitization and dynamic systematic desensitization groups would lead to reductions on the physical damage and separation factors, these were not found. Several possibilities may account for this. It may be that Sarason's (1960) three-factor dynamic theory includes more variables than needed to account for test anxiety; the evaluative factor, which includes fear of criticism and fear of failure, may alone be the underlying dynamic of test anxiety. However, it may also be that the particular items included in the hierarchies in this study were not sufficient to produce reductions in the physical damage or separation factors. The data from this study are not sufficient to evaluate these alternate explanations. Further research is needed to clarify this theoretical issue.

The results of this study provide some basis for understanding the relationship between symptom and dynamic cues to the symptom of test anxiety. Strong support is given for an integrative learning theory which conceptualizes test anxiety as having two independent sources of 
anxiety-- one deriving from the environmental situation itself and the other deriving from conflicts from the past winch are transferred to the present. Of the three theories being considered in this study, on Iy such an integrative theory could account for the reduction in anxiety produced by ail three treatment groups on the performance and self-report test anxiety measures. Sarason's (1960) dynamic hypothesis would have difficulty explaining the significant reductions produced by the symptom group. Similarly, symptom-specific theories (Emery and Krumboltz, 1967; Kondas, 1967) would not be able to explain the reductions produced by the dynamically-oriented groups since the content of these hierarchies would be considered irrelevant to test anxiety.

The advantage of the integrative group was indicated by its consistency across all measures in reducing anyiety. It was not surpassed statistically by either the symptom or dynamic systematic desensitization grolips on any measure and was the only treatment group shown to be efiective in reducing general evaluative anxiety. This finding supports a three-factor theory of test anxiety which not only acknowledges the contribution of independent symptom and dynamic factors but also postulates a third factor which is the result of the interaction of these two independent sources. Concretely, test anxiety is seen as a combination of: 1) symptom anxiety, that is, fear of failure on tests; 2) dynamic anxiety, that is, fear of criticism and 
negative evaluation by parents; and, 3) integrative evaluation anxiety, that is, fear of parental criticism generated by failure on tests. While this theoretical speculation may be accurate, further research from this position is clearly indicated.

This study shows systematic desensitization to be a relatively flexible process for behavior change in that it can utilize content from a variety of theoretical approaches. This study makes a significant contribution in that it demonstrates that systematic desensitization which initially produced a split between behavior therapists and dynamic therapists, can also be used to integrate both approaches. That is, while the process of behavior change is based on conditioning principles, the particular content used to produce such behavior change can come from either a dynamic or behavioral approach. Therefore, as intended, this research is a step in re-integrating an unnecessary split in clinical theory and practice. 
Alpert, R. \& Haber, $R$. Anxiety in academic achievement situations. J. of Abrormal and Social Psych., $1960, \underline{66}, 20 \overline{7}-216$.

Bates, H. Factorial structure and mmpi correlates of a fear survey schedule in a cinical population.

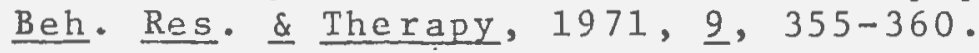

Donner, L. \& Guerney, B. Automated group desensitization for test anxiety. Beh. Res. \& $\underline{\text { Ther., }} 1969, \underline{7}, 1-14$

Elenewski, J. A study of insomnia: the relationship of psychopathology to sleep disturbance. Diss. Abs. Int 1. , 1971, 32, 3631-3632.

Emery, J. Evaluation of standard versus individualized hierarchies in desensitization to reduce test anxiety. Diss. Abs., 1967, 2ㄱ, 2510-2511.

Emery, J. \& Krumboltz, J. Standard versus individualized hierarchies in desensitization to reduce test anxiety. J. of Counseling Psvch., 1967, 14, 204-209.

Feather, E. \& Rhoads, J. Psychodynamic behavior therapy. Arch. Ger. Psychiat., 1972, 26, 503-511.

Freeling, N. \& Shemberg, K. The alleviation of test anxiety by systematic desensitization. Beh. Res. \& Therapy, $1970, \underline{8}, 293-300$.

Hancur, $W . \&$ Prochaska, J. The effectiveness of symptom and dynamic cues in the systematic desensitization of test anxiety. Unpublished manuscript, University of Rhode Island, Kingston, R. I., 1973

Hogan, R. Implosive therapy in the short term treatment of psychotics. Psychotherapy: Theory, Res. $\underline{\varepsilon}$ Prac., $1966, \underline{3}, \widehat{25-31}$.

IhIi, K. \& Garlington, W. A comparison of groups versus individual desensitization of test anxiety. Beh. Res. \& Therapy, 1969, $\underline{7}, 207-210$

Kamil, L. Reduction of castration fear through implosive treatment of a snake phobia. I. of Abnorm., 1970 , 16, $199-203$. 
Kondas, L. Reduction of exam anxiety and stage fright by group desensitization and relaxation. Beh. $\underline{\text { Res. }} \underline{\&}$ Therapy, $1967, \underline{5}, 275-281$.

Lazarus, A. Group therapy of phobłc disorders by

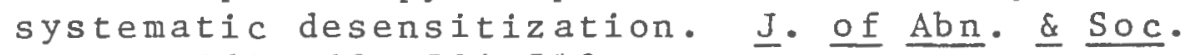
Psy., 1961, 63, 504-510.

Levis, D. Implosive therapy, Part II: The subhuman analogue, the strategy, and the technique. In S. G. Armitage (ed.), Behavior modification techniques in the treatment of emotional disorders: Battle Creek, Mich.: V. A. Publication, 1967 .

Prochaska, J. Symptom and dyrawic cues in the implosive treatment of test anxiety. J. of AbnormaI Psych., 1971, 77, 133-142.

Sarason, S., Davidson, K., LighthalI, F., Raite, R. \& Ruebush, B. Anxiety in elementary school Children., New York: John Wiley, 1960 .

Stampf1, T. \& Levis, D. Essentials of implosive therapy: a learning-theory-based psychodyramic behavioral therapy. J. of Abnormal Psych., 1967, 22, 496-503.

Suinn, R. The desensitization of test-anxiety by group and individual treatment. Beh. Res. \& $\underline{\text { Ther. }}, 1968, \underline{6}$, 385-7.

Wilkins, W. Desensitization: Social and cognitive factors underlying the effectiveness of Wolpe's Procedure. Psych. BuI1., 1971, 76, 31.1-317.

Wolpe, J. Psychotherapy by reciprocal inhibition. Stanford: Stanford University Press, 1958 .

Wolpe, J. The practice of Behavior Therapy. New York: Pergamon Press, Inc. 1973 . 


\section{APPENDIX A}

List of Wolpe Fear Inventory items separated into physical damage, evaluation and separation factors. 
List of Wolpe Fear Inventory items separated into physical damage, evaluation and separation factors.

\section{Physical Damage Factor}

Human blood

Receiving injections

Seeing others injected

Blood from animals

Witnessing surgical operations

open wounds

Medical odors

Prospect of surgical operation

Dentists

High places on 1 and

Doctors

\section{Evaluation Factor}

Looking foolish

Feeling rejected by others

Losing control

Making mistakes

Being ignored

Feeling disapproved of

Being criticized

Failure

Parting from friends

Angry people

One person bullying another

Being teased

Being watched working

Feeling angry

Sudden noises

Being in a strange place

Crowds

Sight of fighting

Ugly people

Dull weather

\section{Separation Factor}

Journeys by bus

Journeys by train

Being in an elevator

Automobiles

Journeys by car

Imaginary craatures 
Sight of deep water Enclosed places

Cemeteries

Thunder

Dead people

People in authority

Dead animals 


\section{APPENDIX B}

1. Raw data and source table for the Wonderiic Personnel Test

2. Raw data and source table for the Wolpe Fear Thermometer

3. Raw data and source table for the Alpert-Haber Text Anxiety Scale

4. Raw data and source table for the Wolpe Fear Inventory

5. Kaw data for the physical damage factor of the Wolpe Fear Inventory

6. Raw data for the evaluation factor of the Wolpe Fear Inventory

7. Raw data for the separation factor of the Wolpe Fear Inventory 
1. Raw data and source table for Wonderlic Fersonnel Test Pretest Scores

$\begin{array}{rllll}\underline{S} & \text { ID } & \text { DD } & \underline{\text { SD }} & \text { NT } \\ 1 & 23 & 23 & 28 & 29 \\ 2 & 22 & 19 & 22 & 14 \\ 3 & 22 & 29 & 24 & 41 \\ 4 & 18 & 27 & 32 & 26 \\ 5 & 23 & 31 & 29 & 33 \\ 6 & 33 & 33 & 23 & 35 \\ 7 & 26 & 30 & 31 & 30 \\ 8 & 42 & 23 & 33 & 24 \\ 9 & 25 & 30 & 36 & 27 \\ 10 & 27 & 26 & 32 & 29 \\ 11 & 19 & 27 & 20 & 27\end{array}$

Posttest scores

$\underline{\mathrm{s}}$

1

3

4

5

6

7

8

9

10

11
ID

26

28

24

18

30

38

26

45

24

27

18
DD

31

19

36

31

35

32

28

26

35

27

28
$\underline{S D}$

34

24

28

39

35

31

33

37

38

32

23
$\mathrm{NT}$

30

15

41

29

30

34

31

19

28

31

26

\begin{tabular}{l|c|c|c} 
Source & SS & df & MS \\
\hline Treatrents & 96 & 3 & 32
\end{tabular}$\quad$ F=4.2496


2. Rew data and source table for

Wolpe Fear Thermometer

Pretest Scores

$\begin{array}{rrrrr}\underline{S} & \underline{I D} & \underline{D D} & \underline{S D} & \underline{N T} \\ 1 & 100 & 55 & 60 & 65 \\ 2 & 55 & 80 & 25 & 25 \\ 3 & 45 & 75 & 50 & 63 \\ 4 & 50 & 63 & 50 & 74 \\ 5 & 75 & 83 & 64 & 62 \\ 6 & 25 & 75 & 75 & 62 \\ 7 & 66 & 86 & 77 & 59 \\ 8 & 92 & 54 & 75 & 50 \\ 9 & 55 & 50 & 25 & 88 \\ 10 & 75 & 75 & 50 & 57 \\ 11 & 68 & 75 & 75 & 43\end{array}$

Posttest Scores

$\begin{array}{rrrrr}\text { S } & \text { ID } & \underline{D D} & \underline{S D} & \underline{N T} \\ 1 & 50 & 25 & 28 & 88 \\ 2 & 0 & 60 & 20 & 25 \\ 3 & 20 & 25 & 25 & 25 \\ 4 & 50 & 18 & 50 & 70 \\ 5 & 25 & 21 & 0 & 63 \\ 6 & 25 & 25 & 50 & 57 \\ 7 & 39 & 11 & 47 & 71 \\ 8 & 63 & 32 & 21 & 50 \\ 9 & 25 & 25 & 25 & 75 \\ 10 & 37 & 38 & 25 & 54 \\ 11 & 43 & 26 & 50 & 57\end{array}$

\begin{tabular}{|c|c|c|c|c|}
\hline Sourca & S S & $d f$ & MS & \\
\hline Treatnents & 9,904 & 3 & 3,301 & \\
\hline Error & 13,552 & 40 & 339 & \\
\hline
\end{tabular}


3. Raw date and source teble for

$$
\begin{gathered}
\text { Alpert-Haber Test Anxiety Scale } \\
\text { Pretest Scores }
\end{gathered}
$$

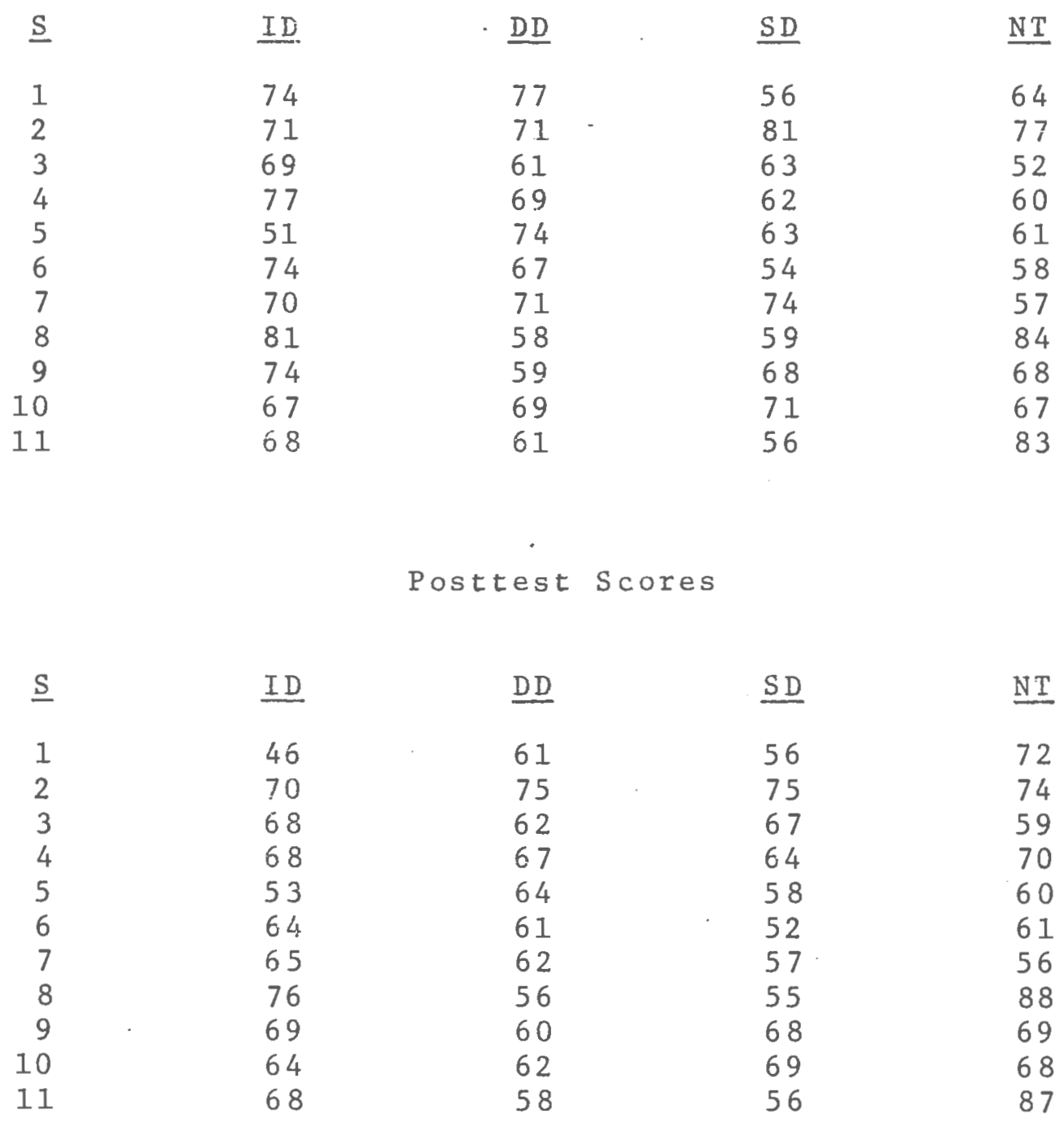

\begin{tabular}{l|c|c|c} 
Source & SS & df & MS \\
\hline Treatments & 505 & 3 & 168 \\
Error & 1.602 & 40 & 40 \\
\hline
\end{tabular}


4. Kaw data and source table for

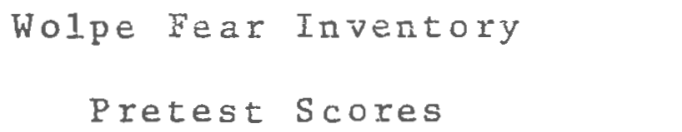

\begin{tabular}{rrrrr} 
S & ID & \multicolumn{1}{c}{ DD } & SD & NT \\
1. & 121 & 105 & 108 & 92 \\
2 & 112 & 100 & 108 & 76 \\
3 & 116 & 129 & 110 & 95 \\
4 & 123 & 112 & 77 & 92 \\
5 & 105 & 93 & 112 & 78 \\
6 & 101 & 93 & 97 & 58 \\
7 & 100 & 140 & 103 & 107 \\
8 & 137 & 82 & 95 & 64 \\
9 & 129 & 138 & 89 & 116 \\
10 & 107 & 99 & 74 & 97 \\
11 & 94 & 131 & 133 & 103
\end{tabular}

Posttest Scores

\begin{tabular}{rrrrr} 
S & \multicolumn{1}{c}{ ID } & \multicolumn{1}{c}{ DD } & \multicolumn{1}{c}{ SD } & NT \\
1 & 71 & 80 & 92 & 116 \\
2 & 106 & 108 & 94 & 80 \\
3 & 66 & 129 & 120 & 89 \\
4 & 99 & 110 & 72 & 104 \\
5 & 120 & 80 & 83 & 84 \\
6 & 99 & 91 & 97 & 55 \\
7 & 102 & 128 & 112 & 98 \\
8 & 104 & 76 & 108 & 75 \\
9 & 131 & 136 & 71 & 113 \\
10 & 94 & 109 & 85 & 85 \\
11 & 101 & 134 & 125 & 86
\end{tabular}

\begin{tabular}{l|c|c|c} 
Source & SS & df & MS \\
\hline Treatments & 1,224 & 3 & 408 \\
Errox & 7,452 & 40 & 186
\end{tabular}


5. Raw data for the physical damage factor of the Wolpe Eazr Inventiry

$$
\text { Pretest Scores }
$$

$\begin{array}{rl}\underline{S} & \underline{I D} \\ 1 & 22 \\ 2 & 24 \\ 3 & 28 \\ 4 & 31 \\ 5 & 26 \\ 6 & 24 \\ 7 & 27 \\ 8 & 38 \\ 9 & 35 \\ 10 & 22 \\ 11 & 17\end{array}$

$\underline{D D}$
18
20
29
18
18
16
36
20
27
19
40

$\underline{\mathrm{SD}}$

$\underline{N T}$

22

24

28

26

24

27

38

35

22

7

25

14

30

15

22

25

22

21

18

20

38

28

22

14

32

17

14

28

13

21

13

26

Posttest Scores

$\underline{\mathrm{S}}$

1

2

3

4

5

6

7

8

9

10

11
ID

14

32

17

24

35

25

32

36

35

17

19
$\underline{\mathrm{DD}}$

13

25

29

16

18

19

35

22

35

19

40
SD

15

14

38

17

18

25

26

27

14

20

37
NT

20

14

26

16

20

12

23 
6. Raw data for the evaluation factor of the Wolpe Fear Inventory

Pretest Scores

$\begin{array}{rrrrr}\underline{S} & \underline{I D} & \underline{D D} & \underline{S D} & \underline{N T} \\ 1 & 72 & 67 & 66 & 47 \\ 2 & 61 & 57 & 73 & 36 \\ 3 & 59 & 66 & 52 & 37 \\ 4 & 64 & 63 & 43 & 41 \\ 5 & 52 & 56 & 66 & 44 \\ 6 & 53 & 59 & 52 & 31 \\ 7 & 52 & 73 & 56 & 53 \\ 8 & 62 & 40 & 54 & 37 \\ 9 & 71 & 78 & 51 & 73 \\ 10 & 64 & 55 & 36 & 67 \\ 11 & 56 & 61 & 69 & 49\end{array}$

Posttest Scores

$\begin{array}{rllll}\underline{S} & \underline{I D} & \underline{D D} & \underline{S D} & \underline{N T} \\ 1 & 39 & 51 & 60 & 60 \\ 2 & 48 & 59 & 60 & 38 \\ 3 & 33 & 67 & 52 & 47 \\ 4 & 53 & 67 & 38 & 49 \\ 5 & 60 & 43 & 46 & 46 \\ 6 & 49 & 55 & 49 & 27 \\ 7 & 46 & 63 & 59 & 50 \\ 8 & 47 & 36 & 61 & 43 \\ 9 & 71 & 68 & 41 & 75 \\ 10 & 56 & 64 & 45 & 57 \\ 11 & 57 & 65 & 63 & 39\end{array}$


7. Raw data for the separation factor on the Wolpe Fear Inventory

Pretest Scores

\begin{tabular}{|c|c|c|c|c|}
\hline$\underline{s}$ & $\underline{\text { ID }}$ & $\underline{D D}$ & $\underline{S D}$ & $\underline{\mathrm{NT}}$ \\
\hline 1 & 27 & 20 & 17 & 17 \\
\hline 2 & 27 & 23 & 21 & 18 \\
\hline 3 & 29 & 34 & 28 & 24 \\
\hline 4 & 28 & 31 & 19 & 19 \\
\hline 5 & 27 & 19 & 24 & 17 \\
\hline 6 & 24 & 18 & 20 & 13 \\
\hline 7 & 21. & 31 & 25 & 26 \\
\hline 8 & 37 & 22 & 20 & 14 \\
\hline 9 & 23 & 33 & 20 & 22 \\
\hline 10 & 21 & 25 & 18 & 17 \\
\hline \multirow{2}{*}{11} & 21 & 30 & 26 & 28 \\
\hline & \multicolumn{3}{|c|}{ Posttest Scores } & \\
\hline$\underline{\mathrm{S}}$ & $\underline{I D}$ & $\underline{\mathrm{DD}}$ & $\underline{\mathrm{SD}}$ & $\underline{N T}$ \\
\hline 1 & 18 & 16 & 17 & 22 \\
\hline 2 & 26 & 24 & 20 & 20 \\
\hline 3 & 16 & 33 & 30 & 22 \\
\hline 4 & 22 & 27 & 17 & 22 \\
\hline 5 & 25 & 19 & 19 & I 8 \\
\hline 6 & 25 & 17 & 23 & 14 \\
\hline 7 & 24 & 30 & 27 & 22 \\
\hline 8 & 21 & 18 & 20 & 16 \\
\hline 9 & 25 & 33 & 16 & 18 \\
\hline 10 & 21 & 26 & 20 & 16 \\
\hline 11 & 25 & 29 & 25 & 24 \\
\hline
\end{tabular}

